\title{
A comprehensive review on integrating renewable energy sources into smart grid : Challenges and Solutions
}

\author{
Jigar Sarda ${ }^{1}$, Kartik Pandya ${ }^{1}$ \\ ${ }^{1}$ Department of Electrical Engineering, C.S. Patel Institute of Technology, \\ CHARUSAT, Changa, Gujarat, India \\ 1jigarsarda.ee@charusat.ac.in \\ ${ }^{1}$ kartikpandya.ee@charusat.ac.in
}

\begin{abstract}
Smart grid is considered as future grid having numbers of advantages, not only for owners but customers also. One of the advantages of this future grid is, it is more reliable and environment-friendly grid as it helps to reduce greenhouse gases emission by integrating renewable energy sources with it. Renewable integration brings lots of benefits but before that numbers of challenges are needed to be solved and hence large-scale renewable penetration is considered as one of the biggest challenges to future smart grid. Researches are going on to deal with these hurdles and to make this integration obstacle-free. This paper presents a literature survey on these challenges and their possible solutions to give a brief view on current research scenario on this topic.
\end{abstract}

Keywords: Energy Storage System (ESS), Phase Locked Loop (PLL), Renewable Energy Sources (RES), Smart Grid (SG), Static Synchronous Compensator (STATCOM).

\section{INTRODUCTION}

A power grid can be explained as a well-designed network through which generated power travels from utilities to our homes (to end users we can say) by means of transmission and distribution lines. As the former line suggest there is unidirectional flow right from utility to end user but when concept of 'smartness' is tempting every field, thought of smart (bidirectional) communication captures the attention. Such a grid where bidirectional communication, means communication between utility to user as well as user to utility is possible can be defined as 'smart grid'. A simple grid consist of generation, transmission and distribution only whereas smart grid is a perfect combination of smart generation, smart transmission, and smart distribution in addition with smart metering, smart infrastructure, smart management, smart communication and numbers of smart sensors. This smart grid is aimed to play an important role for clean energy, efficient transmission of electricity, integration of large scale renewable energy storages, restoration at faster rate after power disturbance and more with the help of self-monitoring and self-healing techniques. It assures the reliability, stability and security of the system.

With the drastic increase in energy demand, smart grid assures the fulfilment of energy demand in a customer friendly manner. If we talk about energy demand, global demand of energy is expected to climb $25 \%$ by 2040. As fossil fuels are predicted to be wane within some decades, smart grid is encouraging the use of clean and illimitable energy. The solution of such problems (increase in energy demand, need of pollution-free generation of energy and limited amount of fossil fuels) is integration of renewable energy sources on large scale. These sources can be replenish with the passage of time and can help to produce the energy which does not harm the environment- hence, best solution for increasing demand. There is no doubt that renewable energy sources (RES) are boon for power grid for generation of electrical energy but as there are always two sides of coin, integration of RES with existing grid is one of the major challenges to the grid. Numbers of technical challenges such as uncertain nature of RES (especially for wind and solar radiations), voltage fluctuation, harmonic distortion, energy storage systems, forecasting, synchronization of voltage and frequency, security, reliability, lack of standards and stability are there. In addition to technical challenges other problems such as economic challenges- energy conversion cost, cost allocation, cash flow and social challenges- demand side management, customer's involvement needs to be settle down.

[1] Was presented to express the importance of smart grid for a sustainable future. In this paper author presented smart grid as an emission-free grid where multidirectional power flow and information exchange is possible. They described smart grid, its major factors due to which it will be smart and also provided the comparison of existing grid with future smart grid. The authors tried to give a glace on a work which is being conducted in America, Canada and Australia for smart grid. The block diagram and model of smart grid with certain issues which needs to be solved to fulfill the dream of smart grid- are providing vital information for new learners. 
In [2], smart grid is explained with distributed generation, making distributed generation as a point of attraction. They simply mentioned that this dream grid will have features which we don't have currently hence called 'smart'. Authors also listed modern hardware as well as modern control systems which will be heart of future smart grid. They also provide brief description of Wide Area Monitoring Systems (WAMS), Supervisory Data Control and Acquisition (SCADA) system, Automatic Metering Infrastructure (AMU) and intelligent electronics devices (IEDs).

As smart grid is considered future grid with green energy, it necessitates penetration of large scale RES. For that different RES are available such as solar, wind, hydro, bio-mass, and geo-thermal and tidal. Every source is having its own specialty and place of availability. These all RES are explained in [3] which give a brief overview of smart grid. With some case studies and based on that studies the future requirements for smart grid is discussed in paper with current trend of researches of this field. As RES integration on large scale comes to picture or when it is considered as distributed generators (DGs), many challenges come to picture. Some of challenges such as voltage fluctuation, reactive power compensation, demand side management, harmonic distortion, forecasting, flexibility and stability of system and storage system are explained in [4] in very well manner. Authors used machine learning technique to develop a prediction model. Except RES integration, other challenges such as cyber security, data privacy, immature technology, lack of infrastructure, market uncertainty, lack of innovation in industries and regulatory framework are also areas of research on which many researchers are working currently [5-8]. [40, 47, 48] gives a brief view on challenges to be solved for SG integration with RES.

This paper gives a brief survey of literature for smart grid challenges and their solution for RES integration. Paper aims to gather maximum recent researches being conducted in the field. Second section of paper briefly describes literature related to smart grid, section III is explaining current status and future expectations from RES in brief, challenges and their solutions are discussed in section IV and section V respectively. At the end, whole paper is concluded in section VI.

\section{SMART GRID}

The network of transmission and distribution lines which connect owner and consumer can be defined as electric grid. Here owner is supplying the energy and consumer is using that energy by traditional grid but what if end user contributes as an owner? How it is possible? The answer of such questions lead to a concept of some grid which gives platform to users to play both roles of user as well as owner by integrating distributed energy resources (DER) is known as 'smart grid'. One can find numbers of work being done on concept of smart grid from literature.

With the incidence of some F-15 plane crash of 1980's, [9] presented a revolutionary idea for our power system which can make them 'smart'. They provided the basic ideas that if we do so, we can make our transmission system smart, benefits of adopting intelligent processors to the system, introduction of SCADA system for diagnostic monitoring for transmission equipment, grid computing, making system self-healing and many more ideas- which are considered as the fundamental building blocks of smart grid today. This was one of the earlier papers (very first paper) giving a new concept of smart grid (SG).

As renewables are part of SG, reduction in total greenhouse gas emission along with demand management makes system more reliable and efficient [1]. This paper also provides information about development status of SG in America and Europe. A review of SG was made in [10] including brief architecture of SG, explaining effectiveness of dynamic optimal power flow (DOPF) for system efficiency of future SG by comparing computational efficiency results of DOPF and COPF (centralize optimal power flow). This paper is giving a brief discussion on power loss by comparing different algorithms, by comparing power loss at different loadings, comparing effects of introducing distributed generators to a system for power loss. As to mitigate the costumer's energy demand is another task for SG, authors also include storage system, demand side management, load shedding and generation scheduling. To mitigate Indian scenario of RES integration [49] presented a novel work on SG challenges for India.

If we talk about RES integration with SG, PV and wind are sources which are centre of attraction today for everyone because they are available almost everywhere. [11] Gives a basic introduction of smart grid and then connection of RES, mainly PV system with three types of inverters named string inverter, central inverter and micro inverter. Authors proposed a new topology of transformer less inverters for easy integration with SG. A review paper on smart grid energy security [12] gave the review on RES, digits of world energy consumption, SG and explained how integration of RES with SG can improve safety and security of electrical system. Paper also gave the brief review on different RES and their integration with SG and on other hand [58] presents a review for smart grid and RES integration which is supposed to support by means of Electrical vehicles. 


\section{RENEWABLE ENERGY RESOURCES - CURRENT SCENARIO}

According to International Energy Agency (IEA) report [13] contribution of RES for electricity sector which is $23.9 \%$ in the year of 2017 , will increase to $29.4 \%$ in 2023 . According to [14] share of RES for global energy production will be more than $50 \%$ by 2050 from which solar PV and wind energy will contribute $35.8 \%$ and $36.4 \%$ respectively. The energy generation from RES within last decade [15] is expressed in figure 1 which shows exponential increase in utilization of RES. Figure 2 shows the contribution of different RES sources for total electricity generation. [40] Discuss about benefits of photovoltaic generation at too much large scale such as terra-watt level, also challenges are there and hence explains both benefits as well as challenges.

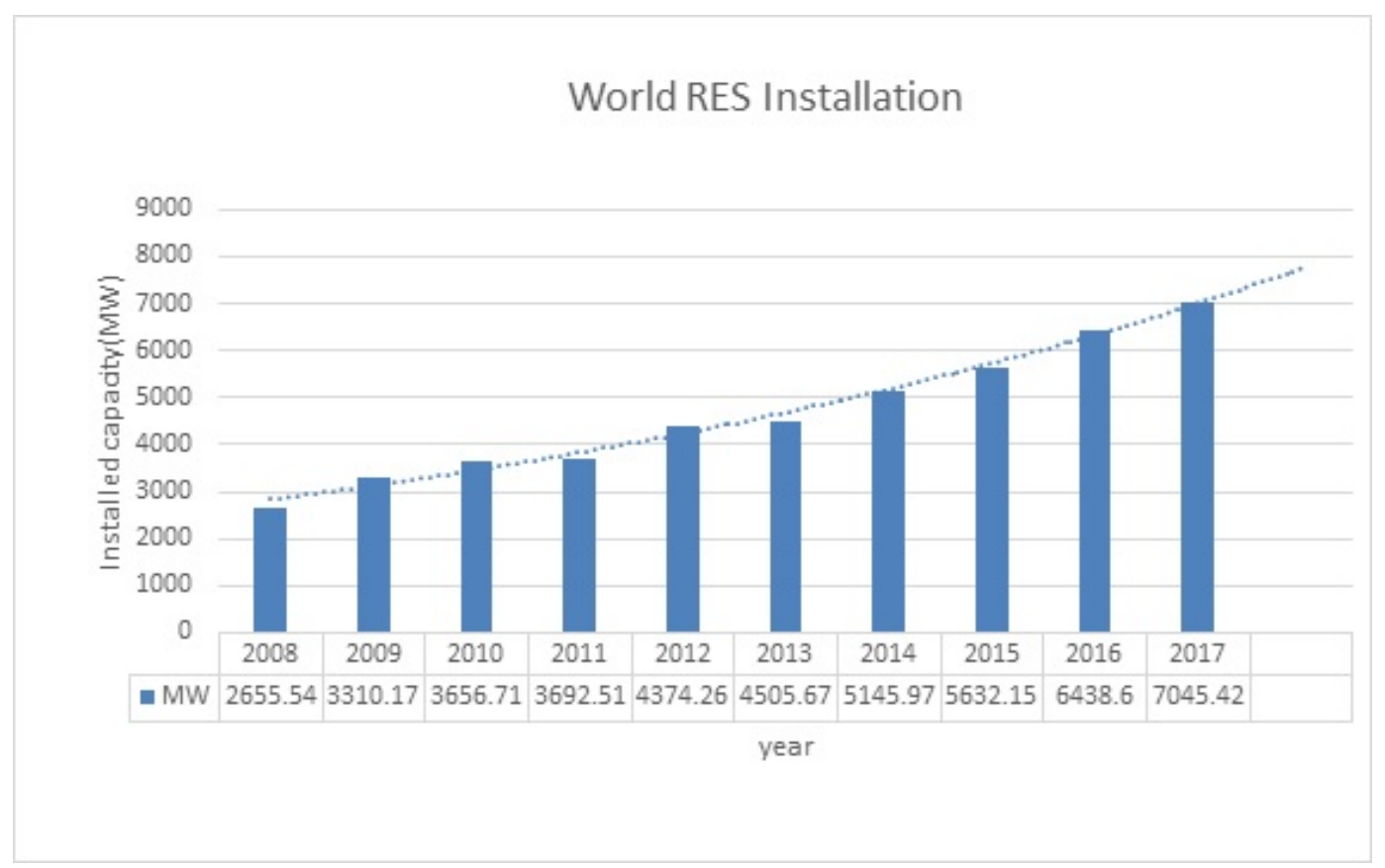

Fig. 1 RES contribution of electricity generation year-wise

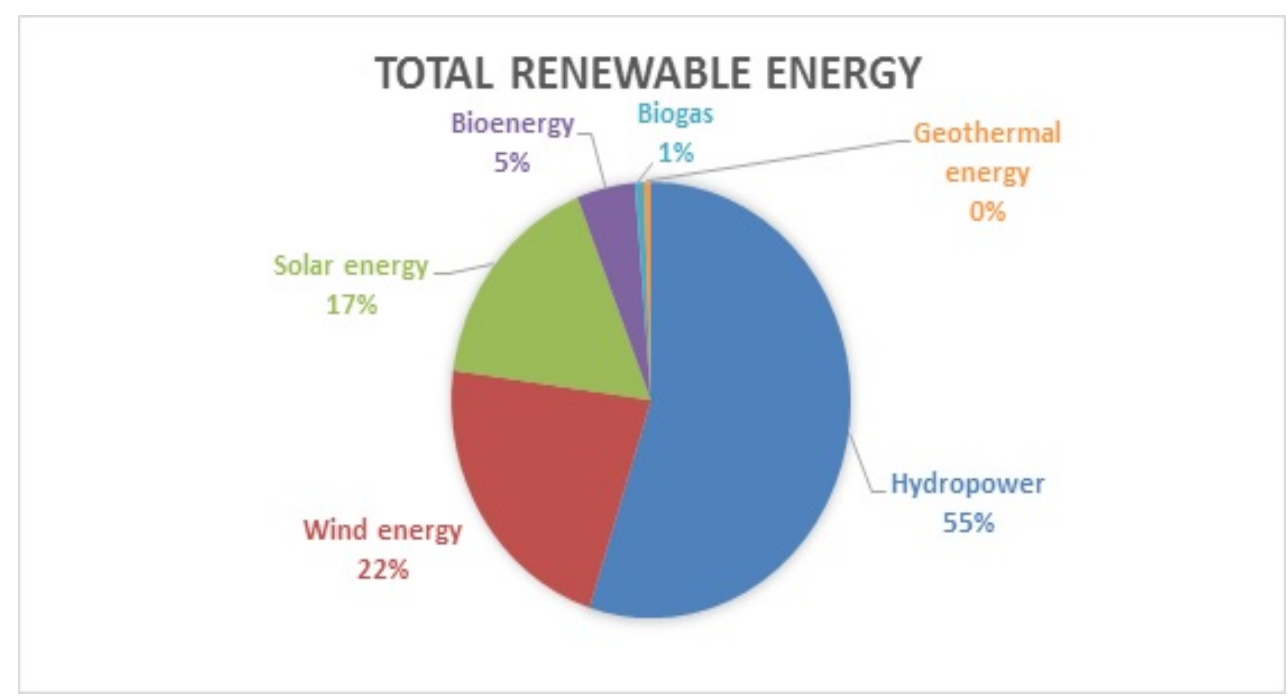

Fig. 2 Contribution of different RES sources in total RES contribution- 2018

The data above shows the importance of RES and their integration effect on future SG. [25] Describes the integration of RES with future SG, its applications and challenges in brief and [26] gives a review on challenges and its possible solutions for the same based on scenario of India. By utilization of RES and SG, concept of smart home in pudducherry is studied in [27]. 


\section{CHALLENGES OF INTEGRATING RES}

As section II increase the attraction towards smart grid and section III describe the worth of RES, interest of integrating RES with future SG may reach to its highest level. Of course, SG will be intelligent enough to deal with its distributed generations means RES but today there are many challenges which we need to solve before penetrating RES in SG. Authors of [16] explained concept of SG and described challenges to SG such as protection of Future Renewable Electric Energy Delivery and Management (FREEDM) system, need of efficient communication system, operating the electric grid with high proportion of RES, monitoring and control, preparations of Electrical vehicles as a plug-in hybrid vehicles. Also, concerns with emerging RES to SG such as uncertainty, distance from load centres, voltage fluctuations and storage requirement are explained. Figure 3 show some of these challenges which are discussed in brief.

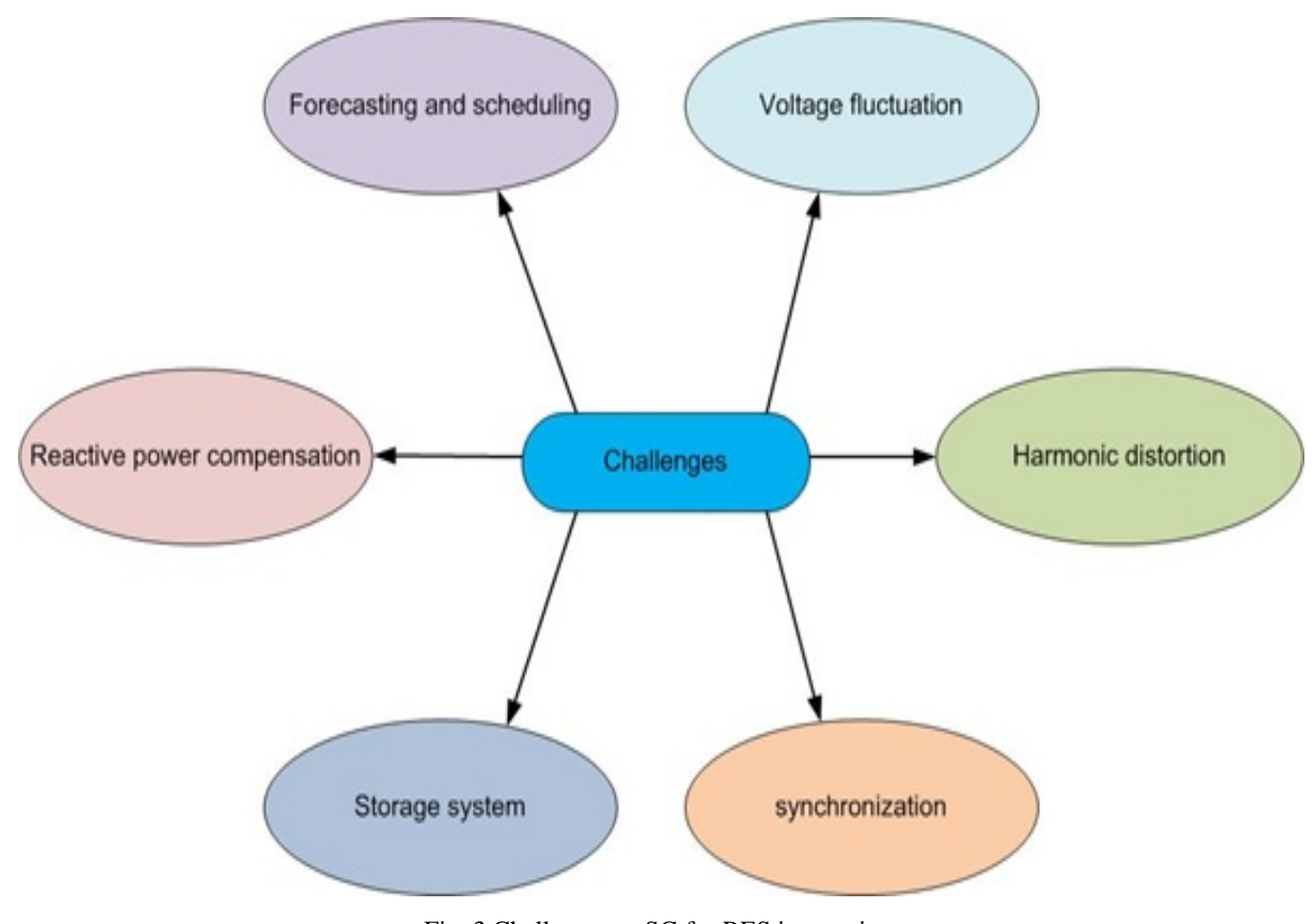

Fig. 3 Challenges to SG for RES integration

\section{A. Voltage fluctuation}

The undesirable random changes in voltage level which might be end up with impairment of device is called voltage fluctuation. Renewable sources mainly depend on weather conditions and hence change its potential according to weather situations with respect to time. Overvoltage cause reverse power flow and increased line losses which eventually affects operation of switch-gears and protection within different networks.This voltage fluctuation affects system stability and control because fluctuation in voltage level deteriorate the system stability. Hence, voltage fluctuation is one of the challenges for future SG to be connected with large scale with RES.

\section{B. Energy Storage}

As wind and solar resources are variable in nature, sometimes they generate more than sufficient required energy and sometimes are unable to produce enough energy to fulfill the demand. When RES generation is less than demand, we need some back-up to fulfill customer's demand and on other hand if generation is more than demand, the best option is to store the generated energy somehow to stop the wastage of that energy and to utilize it for future use. The appropriate solution for both cases is- Energy Storage System (ESS). ESS has vast area of its applications by both- technical point of view as well as economic point of view [16], but the main challenge with storage systems is their design. Electrical Energy Storage (EES) are designed for particular applications, means EES design as a solution of one problem may not be useful for another problem. So each case needs its special strategy of solution. As a result it consumes huge amount of time and also increase the level of cost [8]. Also if we talk about batteries for storage, the size of battery also comes to picture when large scale storage is required. So optimization of battery's size and modelling of battery is also a challenge for storage purpose. 
As numbers of energy storage options are available in market today and some are at developing stage, each having its own characteristics and area of application- there is also a question of selection of correct option for given problem. Hence, selection of EES/ESS with respect to technical, economical and geographical aspects is also a challenge. One another big challenge which storage system is facing for SG integration is their desirable cost so that it can be economically beneficial for customer or utility.

\section{Harmonic distortion}

The RES integration with grid will be possible with the help of numbers of power electronic devices such as inverters and converters. This power electronic devices when operated with nonlinear appliances, injects harmonics to the system. This harmonics distort the voltage and current signals. Hence, create the problem of voltage distortion. This phenomenon supports excessive amount of heat which may adversely affect the power system. As SG design indicates SG will deal with thousands of power electronic devices- harmonic distortion is one the big challenges which SG is supposed to tackle with.

\section{Synchronization}

The ultimate goal of SG is to provide electricity with better power quality to end user. The uncertainty of RES produces power which is also variable in nature and hence needs to be synchronized with grid. There should be synchronization of frequency, phase and voltage level between RES generated power and grid power and if not done so, there might be chances of damage of equipment. Hence, synchronization with grid is one of the challenges.

\section{E. Forecasting and scheduling}

RES, especially wind and solar PV are uncertain by nature as it depends on climate conditions. Integration of such intermittent generation with grid will introduce variability in power and might be require more ancillary services. To deal with such prospects, accurate forecasting is necessary [38]. The forecasting is done by various methods. Numbers of algorithms and numbers of soft-wares are available for forecasting but the challenge is accurate forecasting with accurate timing.

In addition with techniques of forecasting, weather information data, geographical data and past data of event should be available in sufficient quantity so now availability of data and security of data also comes to picture. Once forecasting is done, the demand side management starts playing its important role by scheduling the energy demand and generation. Hence, forecasting and scheduling is another challenge for RES integration Reactive power compensation.

While reduction in reactive power supports power factor improvement and system efficiency, certain amount of this power is a major need to control the voltage and tackle with transmission losses. Hence, to maintain stability of future SG, compensation of reactive power is necessary. As voltage stability itself is a challenge for SG, reactive power compensation is also a challenge to maintain system stability.

\section{POSSIBLE SOLUTION OF CHALLENGES}

This paper is explaining some of the major challenges which SG is facing today to integrate RES. Many researches are going on to deal with these problems and make the dream of future SG with higher contribution of RES possible. Some of these current works is tried to showcase through this paper. During study of different literature for finding solution of these challenges, some of the solutions were able to solve more than one problem. Hence, this section focuses on numbers of solutions available for one or more problems.

\section{A. Electrical Energy Storage(ESS)}

As RES are uncertain in nature- they do not produce constant power due to which voltage fluctuation, synchronization and stability of system challenges the SG. If we introduce storage system to SG as a solution of these problems- it is very beneficial. According to [16], EES provides a critical link between owner and consumer, providing additional capacity to the grid to improve its stability. During explanation of applications of EES [18] one of the applications says that as EES supports active power for stable output, it increases the capability of grid for frequency regulation which is solution of another challenge to SG. Also, as EES provides additional power to the grid- it also helps to enhance system stability, reliability and flexibility along with providing relevance to congestion of transmission lines. The paper also classified energy storages according to the way they store energy, such as mechanical energy storage, heat storage, electrochemical energy storage, electromagnetic energy storage and chemical energy storage as shown in figure 4. Some of the literature also suggested a term named energy storage systems (ESS). Where lot of literature is available to support implementation of EES on large-scale, [59] presented electrical Vehicle as another option of storage supporting element which not only stores electrical energy but also supports voltage stability and reliability of system by giving power back to the grid when necessary. 


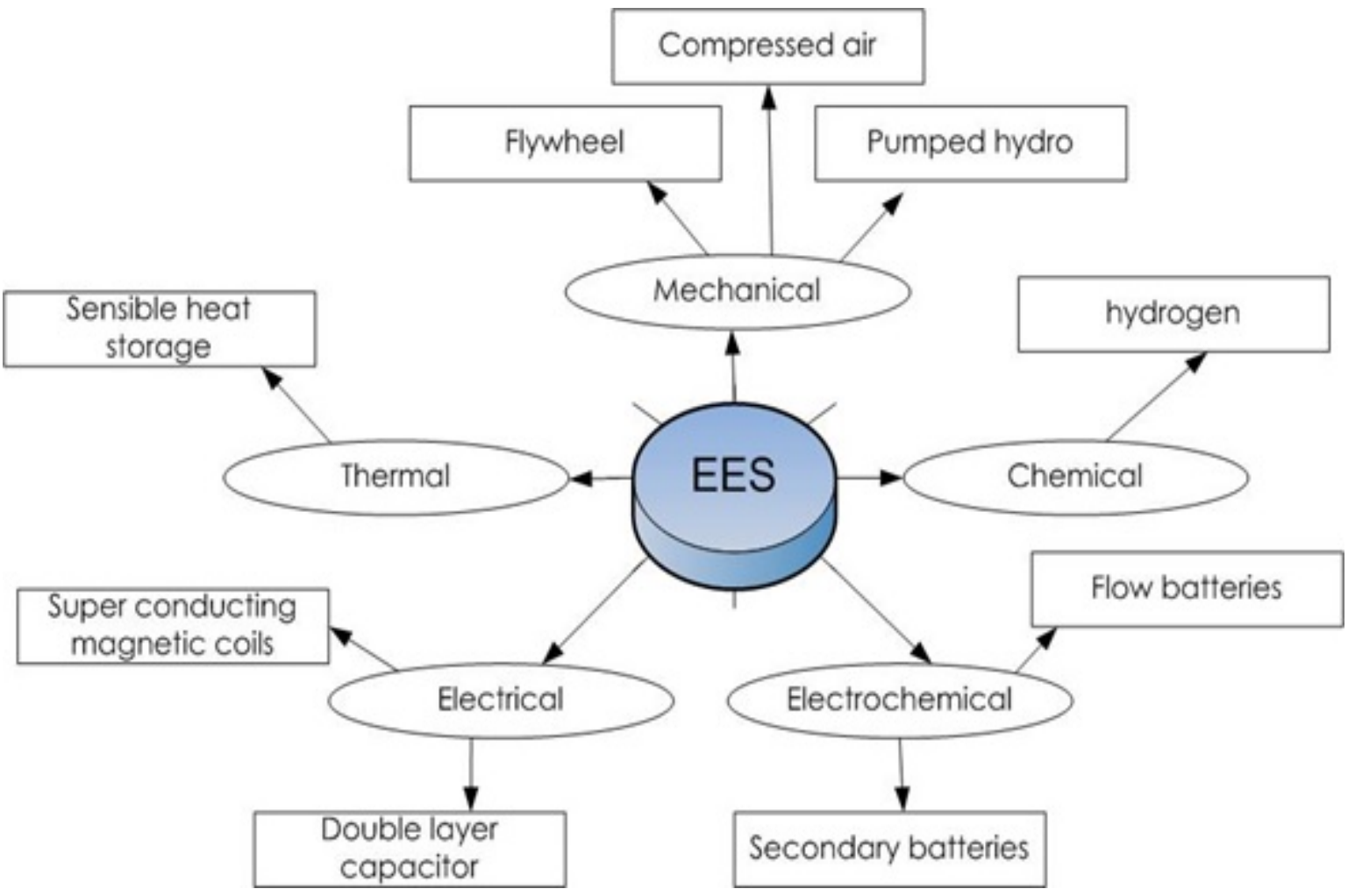

Fig. 4 Classifications of EES

Along with these so called traditional storage systems, [19] represented hybrid energy storage systems (HESS) as a coupling of two or more energy storage systems. This paper begins with comparison of different storage elements and specialty explanation of some of them. The coupling can be done by many approaches from one of the simplest method is direct DC coupling of storage elements. Although this method has its own disadvantages, architecture of coupling with the help of one DC/DC converter (bidirectional) connected to high power storage. Concepts and applications of HESS are also explained in very well manner.

One of the most popular storage elements is a battery. Different types of batteries are available in market for different perspectives such as lead-acid batteries, lithium batteries and many more. Of course, some of the batteries are at research phase with much more advantages. With the vast information of some current installations of 'big batteries' (such as battery built by Tesla in Australia [60]), [20] discussed on battery energy storage systems (BESS) with well explanation of lithium-ion batteries as a better storage option against leadacid batteries. Also limitations of lithium-ion batteries, how its lifetime gets down and safety methods are expressed in brief along with large scale introduction of storage systems and related policies which can help to tackle with such problems are expressed.

Where [20] explain benefits of using lithium-ion batteries on small as well as large scale, a new idea of 'artificial photosynthesis' for energy is proposed in [21], this method presents an approach by which energy is produced and in addition it supports some biological processes for example making food and more. As discussed in section IV (B), the size and modelling of battery is also a big challenge to be solved. Because of by many reasons lithium-ion batteries are being more famous for energy storage, its modelling for cell life assessment is explained in very gentle way in [23] and to tackle with battery sizing issue, [24] proposed Particle Swarm Optimization as sizing algorithm for a hybrid storage system employing PV, battery and $H_{2}$. Till now if the question of how many challenges we can solve by using storage systems wander in mind, the various fields of answer are frequency regulation, reactive power support, black start, capacity improvement and more [22].

\section{B. STATCOM device}

When it comes to system's voltage stability and harmonic impact from RES, another question of reactive power compansetion also plays an important role as a challenge and their possible solution might be Static Synchronous Compensator (STATCOM) device which is one of the members of FACTS family [28]. [29] presented a new methodology on voltage stability for by cooperating STATCOM at distribution side. Authors modelled a system of microgrid with the help of digital simulation and by comparing results of system without and with cooperation of STATCOM. They presented effectiveness of this methodology for voltage stabilization. 
A novel work showing effectiveess of STATCOM for improvement in power quality by voltage stabilization was presented in [30]. Authors developed their results for wind connected system in MATLAB SIMULINK enviornment. The use of STATCOM for unbalaced power system by taking care of positive sequence voltage and negative sequence voltage at the point of common coupling (PCC) as a PCC controller was discussed in [31]. Another work of STATCOM utilization is presented in [32,36,43].

The nobel work for utilization of STATCOM as multipulse STATCOM was explained in [33], the results shows that implimentation of this device reduces the current harmonics from $13.44 \%$ to $1.37 \%$. [34] also showed a work for STATCOM application of mitigating the harmonic challenge along with reactive power compansation. The model was analysed and THD (Total Harmonic Distortion) analyzation was also shown in this work.

Not only voltage stability and harmonic distortion, STATCOM is also a solution for synchronization and grid control [35]. Furthermore, [46] explains selective harmonic elimination (SHE) system and its simulation results along with introduction of harmonics in system, its effects and different harmonic elimination techniques. This paper represents a new technique named multilevel selective harmonic elimination pulse-width modulation (MSHE-PWM) for transformer STATCOM system by using cascadle H-bridge inverter.

\section{Forecasting and scheduling methods}

From numbers of RES to be integrated with smart grid, major contributions are and will be from solar and wind sources as wind and solar capacity which are 398 and 515 GW in 2017, are supposed to contribute 2,033 and 1,198 GW respectively in the year of 2035[37]. The biggest obstacle of integrating wind and solar with grid is their uncertain behavior. Hence, forecasting is the solution to deal with such hardels. Basic information of forecasting and importance of forecasting along with various types of forecastings is described in very well manner in[38]. From three vital methods of forecasting (differentiated such as classical stastistical technique, computational intelligent method and hybrid algorithms) time series method- most ususal classical method of forecasting is explained along with their mathematical expressions in [39]. The hybrid probabilistic forecasting model (HPFM) using one of the modified versions of PSO (DEEPSO) is introduced in [42]. Reults were analysed with the help of monte-carlo simulation model with the desire of finding the range of forecasted values without growing the forecast error.

As forecasting of RES very important for SG, the suppliers needs long term as well as short term forecasting for which they need some desirable information from customer side. [43] explains that providers need only some of the data from users and hence they presented a forecasting method which do not disturb user's privacy by their proposed method named group method of data handling (GMDH) with the help of one of the famous algorithms- artificial nuero network. On other hand, a model named Self Exciting Threshold Auto Regressive models with eXogenous regressors (SETARX) was offered by [45] as robust approach for spot prize forecasting of electricity. Paper presented modeling of SETAR, its simulation and prize forecasting for Italy's electricity market. Where a lot of literature is present explaining modeling and their results of forecasting, [50] presented power of optimization algorithms to improve overall forecasting of RES. They presented LSM (least square method) and EMM (energy minimization method) to enhance the forecasting by different case studies.The different time series methods for forecasting is shown in figure 5 [39]. 


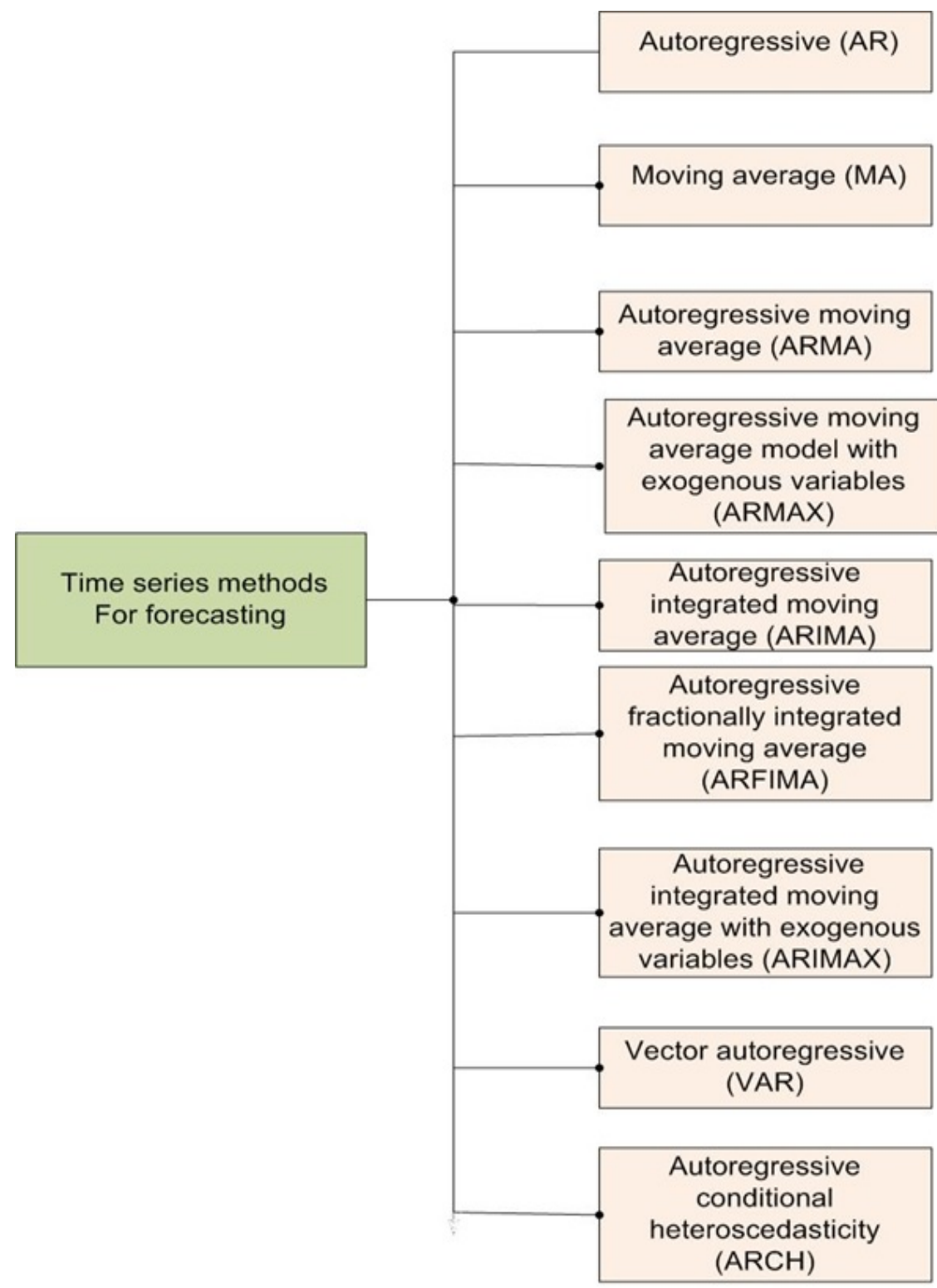

Fig. 5 Time series methods for forecasting

[44] gives a review on challenges and solution for power quality for RES penetration with grid. Also, when comes to power quality, synchronization is also necessary for grid. [51] reviewed different methods of synchronization devided as PLL (Phase Locked Loop) based and non-PLL based techniques. The explained methods as PLL based methods [56] were PLL based on T/4 delay [52], PLL based on hilbert transform [53], PLL based on inverse Park's transform, Enhance PLL [54], Robust single-phase PLL [53], SOGI PLL with the help of SOGI-QSG filter [55] and non-PLL based methods were fourier analysis and inducverters [57].

\section{CONCLUSION}

In this paper, numbers of researches are surveyed to mitigate one of the major challenges of smart grid as large scale renewable integration. Numbers of challenges such voltage fluctuation, harmonic distortion, stability, storage system and forecasting of RES and related literature is explained in brief. The conclusion of this survey leads to the results that some of the presented work can become solution of more than one problem. STATCOM can be represented as a solution of voltage stability, reactive power compensation, synchronization and harmonic distortion. ESS can be solution of system stability, flexibility and voltage fluctuation. Numbers of PLL based and non-PLL based methods are available to solve the problem of synchronization. Forecasting has its own vast area of development to forecast weather conditions, energy demand and energy prizes. 


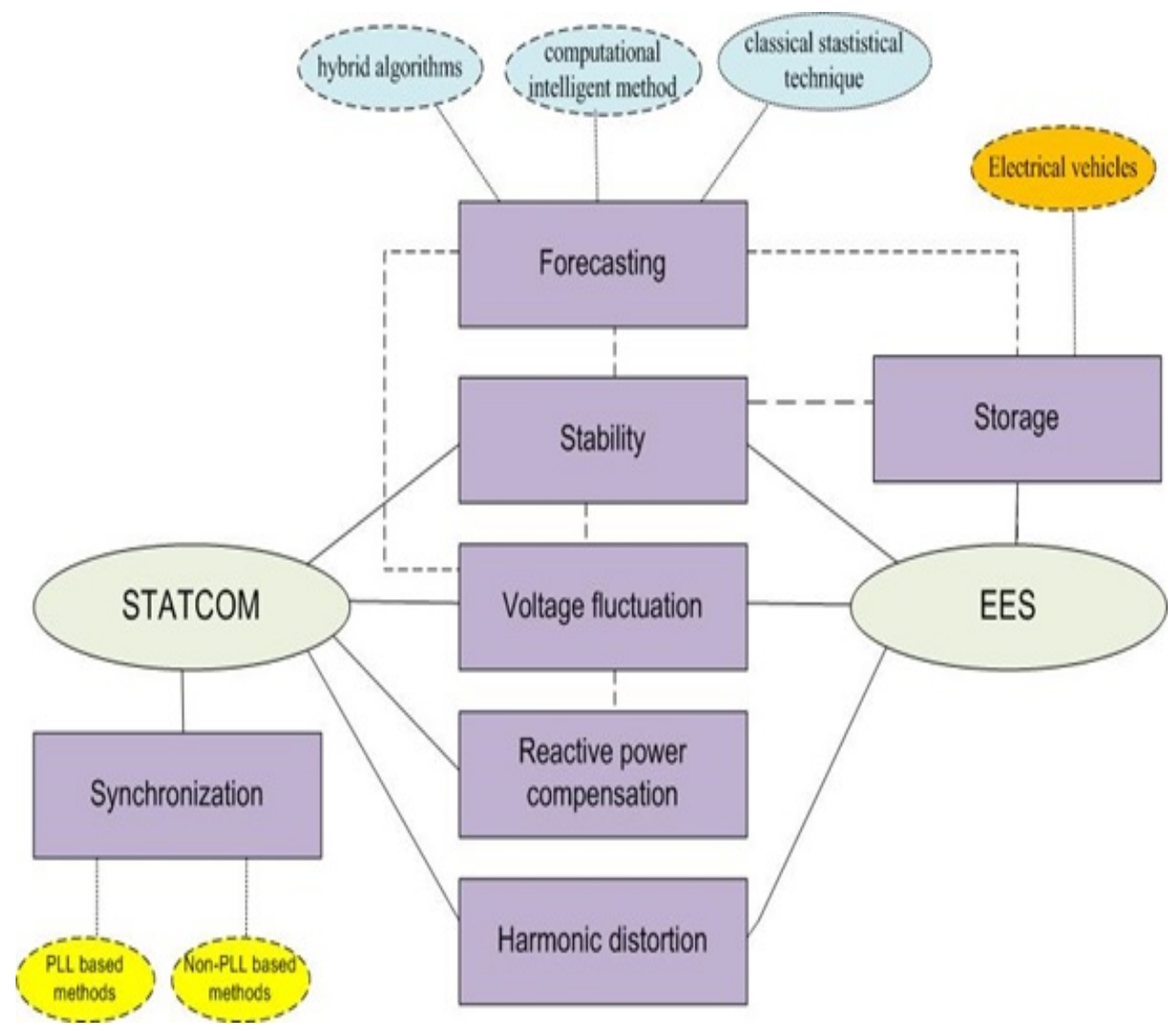

Fig. 6 Graphical representation of conclusion

\section{REFERENCES}

[1] G. M. Shafiullah, Amanullah M. T. Oo, A. B. M. Shawkat Ali, Peter Wolfs, 'Smart grid for a sustainable future', Smart Grid and Renewable Energy, Vol. 4, 2013, http://dx.doi.org/10.4236/sgre.2013.41004

[2] Indrajeet Prasad, 'Smart grid technology: application and control', International Journal of Advanced Research in Electrical, Electronics and Instrumentation Engineering, Vol. 3, Issue 5, May 2014

[3] M.S. Hossain, N.A. Madlool, N.A. Rahim, J. Selvaraj, A.K. Pandey, Abdul fahim khan, 'Role of smart grid in renewable energy: An overview', Renewable and sustainable energy reviews, 2016, http://dx.doi.org/10.1016/j.rser.2015.09.098

[4] GM Shafiullah, Amanullah M. T. Oo, Dennis Jarvis, ABM Shawkat Ali, Peter Wolfs, 'Potential challenges: Integrating renewable energy with the smart grid', $20^{\text {th }}$ australasian universities power engineering conference, New Zealand, IEEE, 2010.

[5] Fatemeh Halim, Salman Yussof, Mohd. Ezanee Rusli, 'Cyber security issues in smart meter and their solutions', International Journal of Computer Science and Network Security, VOL.18, Issue.3, March 2018

[6] Vandana Rohokale, Ramjee Prasad, 'Cyber security for smart grid -The backbone of social economy', Journal of Cyber Security, Vol. 5, pp. 55-76, 2016, doi: $10.13052 /$ jcsm2245-1439.514

[7] David B. Richardson, 'Electric vehicles and the electric grid: A review of modelling approaches, Impacts, and renewable energy integration', Renewable and Sustainable Energy Reviews, Vol. 19, pp. 247-254, 2013, http://dx.doi.org/10.1016/j.rser.2012.11.042

[8] S. Zafar, K. Nawaz, S.A.R. Naqvi, T.N. Malik, 'Integration of renewable energy sources in smart grid: A review', The Nucleus, Vol. 50, Issue. 4, pp. 311-327, 2013, https://www.researchgate.net/publication/315669268

[9] S. Massaud Amin, Bruce F. Wollenberg, 'Towards a smart grid', IEEE power and energy magazine, September-October 2005, doi: 1540-7977/05

[10] S. Hari Charan Cherukuri, Balasubramaniyan Saravanan, 'An overview of selected topics in smart grids', Frontiers in energy, Vol. 10, Issue 4, pp. 441-458, 2016, DOI 10.1007/s11708-016-0418-6

[11] Hania EI-Kanj Baitie, Tarek Selmi, 'Review of smart grid systems' requirements', Tenth International Conference on Ecological Vehicles and Renewable Energies (EVER), 2015, doi: 978-1-4673-6785-1115

[12] M.A. Islam, M. Hasanuzzaman, N.A. Rahim, A. Nahar, M. Hosenuzzaman, 'Global renewable energy-based electricity generation and smart grid system for energy security’, The Scientific World Journal, Article ID 197136, 2014, http://dx.doi.org/10.1155/2014/197136

[13] https://www.iea.org/topics/renewables/

[14] Energy transition outlook 2017, 'renewables, power and energy use forecast to 2050', https://www.ourenergypolicy.org

[15] Renewable energy statics 2018, International Renewable Energy Agency (IRENA), https://www.irena.org/publications/2018/jul/Renewable-Energy-Statistics-2018

[16] Sheetal Munje, 'Renewable energy integration into smart grid- energy storage technologies and challenges', International Research Journal of Engineering and Technology (IRJET), Volume: 04, Issue: 06, June -2017

[17] Engin Ozdemir, Sule Ozdemir, Koray Erhan, Ahmet Aktas, 'Energy storage technologies opportunities and challenges in smart grids', 3rd International Smart Grid Workshop and Certificate Program (ISGWCP), Istanbul, Turkey, March 21-25, 2016

[18] Liangzhong YAO, Bo YANG, Hongfen CUI, Jun ZHUANG, Jilei YE, Jinhua XUE, 'Challenges and progresses of energy storage technology and its application in power systems', J. Mod. Power Syst. Clean Energy, pp. 519-528, 2016, DOI 10.1007/s40565-0160248-x

[19] Thilo Bocklisch, 'Hybrid energy storage systems for renewable energy applications', 9th International Renewable Energy Storage Conference, IRES 2015, doi: 10.1016/j.egypro.2015.07.582 
[20] Thomas A. Faunce, James Prest, Dawei Su, Sean J. Hearne, Francesca Iacopi, 'On-grid batteries for large-scale energy storage: Challenges and opportunities for policy and technology', MRS Energy \& Sustainability: A Review Journal, doi:10.1557/mre.2018.11

[21] Thomas Faunce, 'Global Artificial Photosynthesis and Renewable Energy Storage and Policy for the Sustainocene', Advance Sustainable System, 2018, DOI: 10.1002/adsu.201800035

[22] David Blood, 'Battery based energy storage: The renewable power proliferation enabler', Renewable energy focus, volume 17, Issue 6, November-december 2016, http://dx.doi.org/10.1016/j.ref.2016.10.006

[23] Bolun Xu, Alexandre Oudalov, Andreas Ulbig, Göran Andersson, Daniel S. Kirschen, 'Modelling of Lithium-Ion battery degradation for cell life assessment', IEEE transactions on smart grid, vol. 9, Issue. 2, MARCH 2018, doi: 10.1109/TSG.2016.2578950

[24] Martin Paulitschke, Thilo Bocklisch, Michael Böttiger, 'Sizing algorithm for a PV-battery-H2-hybrid system employing particle swarm optimization’, 9th International Renewable Energy Storage Conference, IRES 2015. doi: 10.1016/j.egypro.2015.07.664

[25] Matthew L. Wakulchik, 'Integrating renewable energy with the grid', Journal of Undergraduate Research 9- 2016, 2017 University of Illinois at Chicago

[26] Abhilash M G, Parvathy P, Divyasree dinesh, 'Renewable energy integration into smart grid: Problems and solutions based on Indian power scenario', International Journal of Scientific \& Engineering Research, Volume 6, Issue 4, April-2015

[27] Surekha S. Bhalshankar, Dr C.S.Thorat, 'Integration of smart grid with renewable energy for energy demand management: Puducherry case study', International conference on Signal Processing, Communication, Power and Embedded System (SCOPES)-2016, 978-15090-4620-1/16

[28] Anwar S. Siddiqui, Tanmoy Deb, 'Congestion management using FACTS devices', International Journal of System Assurance Engineering and Management, DOI: 10.1007/s13198-013-0212-3

[29] Hirotomo Miura, Guohong Wu, 'Voltage stabilization of distribution system integrated by renewable power generations by cooperated control of STATCOM and interconnecting microgrids', International Journal of Smart Grid and Clean Energy, vol. 3, Issue. 1, January 2014

[30] K. Sheshu Kumar, K. Suresh Kumar, Sk Baji, ‘A new control scheme for power quality improvement with STATCOM', International Journal of Engineering Research and Applications (IJERA), Vol. 3, Issue 4, pp.2555-2561, Jul-Aug 2013

[31] Ana Rodríguez, Emilio J. Bueno, Álvar Mayor, Francisco J. Rodríguez, Aurelio García-Cerrada, 'Voltage support provided by STATCOM in unbalanced power systems’, Energies, Vol. 7, pp. 1003-1026, 2014; doi:10.3390/en7021003

[32] Punam Domkawale, V.K. Chandrakar, 'Voltage stability enhancement in large power system by using STATCOM', International Research Journal of Engineering and Technology (IRJET), Volume: 04, Issue: 04, Apr -2017

[33] Rajesh Kr Ahuja, Mukul chankaya, 'A multipulse STATCOM for harmonics elimination in power system', International Journal of Advanced Research in Electrical, Electronics and Instrumentation Engineering, Vol. 1, Issue 6, December 2012

[34] Vandana S Pai, Jo Joy, 'Reactive power compensation and harmonic mitigation in a grid connected system using STATCOM', International Journal of Advanced Research in Electrical, Electronics and Instrumentation Engineering, Vol. 3, Special Issue 5, December 2014

[35] LIU jinning, ZHANG li, CAO man, 'Power management and synchronization control of renewable energy microgrid based on STATCOM’, https://doi.org/10.1109/ITEC-AP.2014.6941242

[36] Hiroshi Yonezawa, Toshiaki Shimato, Michiharu Tsukada, Katsuhiko Matsuno, Isao Iyoda, John J. Paserba, Gregory F. Reed, 'Study of a STATCOM application for voltage stability evaluated by dynamic pv curves and time simulations', doi: 0-7803-5938-0/00

[37] https://enewablesnow.com/news/solar-pv-could-be-global-leader-in-terms-of-capacity-in-2040-iea-633268/

[38] J.M.Morales, 'Renewable energy sources- modelling and forecasting', International series in Operation Research \& management science 205, doi:10.1007/978-1-4614-9411-9_2

[39] Mahmoud Ghofrani, Musaad Alolayan, 'Time series and renewable energy forecasting', Time Series and Renewable Energy Forecasting, http://dx.doi.org/10.5772/intechopen.70845

[40] Nancy M. Haegel, Robert Margolis, Tonio Buonassisi, David Feldman, Armin Froitzheim, Raffi Garabedian, Martin Green, Stefan Glunz, Hans-Martin Henning, Burkhard Holder, Izumi Kaizuka, Benjamin Kroposki, Koji Matsubara, Shigeru Niki, Keiichiro Sakurai, Roland A. Schindler, William Tumas, Eicke R. Weber, Gregory Wilson, Michael Woodhouse, Sarah Kurtz, 'Terawatt-scale photovoltaics: Trajectories and challenges, Coordinating technology, policy, and business innovations' April 2017, http://science.sciencemag.org

[41] Maher Guizani and Muhammad Anan, 'smart grid opportunities and challenges of integrating renewable sources: A survey', 978-14799-0959-9, IEEE, 2014

[42] Gerardo J. Osório, Mohamed Lotfi, Miadreza Shafie-khah, Vasco M. A. Campos, João P. S. Catalão, 'Hybrid forecasting model for short-term electricity market prices with renewable integration', Sustainability 2019, Vol 11, Issue 57; doi:10.3390/su11010057

[43] Claudio A. Cãnizares, Massimo Pozzi, Sandro Corsi, Edvina Uzunovic, 'STATCOM modelling for voltage and angle stability studies’, Electrical Power \& Energy Systems, Vol. 25, 2003

[44] Sonali N. Kulkarni, Prashant Shingare, 'A review on power quality challenges in renewable Energy grid integration', International Journal of Current Engineering and Technology, Vol.6, No.5, Oct 2016, http://inpressco.com/category/ijcet

[45] Luigi Grossia, Fany Nanb, 'Robust forecasting of electricity prices: Simulations, models and the impact of renewable sources', Technological Forecasting and Social Change, January 2019, DOI: 10.1016/j.techfore.2019.01.006

[46] P.S.Sugirtha, Mr. S. Rajan Babu, 'Harmonic distortion elimination for STATCOM application using SHE-PWM cascaded multilevel inverter', International Journal for Research in Applied Science \& Engineering Technology (IJRASET), Volume 4, Issue III, March 2016

[47] Abdulhakim Khalaf Alsaif, 'Challenges and benefits of integrating the renewable energy technologies into the AC power system grid', American Journal of Engineering Research (AJER), Volume-6, Issue-4, pp. 95-100 , 2017

[48] Rabab Hassan, Ghadir Radman, 'Survey on Smart Grid', 978-1-4244-5853-0, IEEE, 2010

[49] Dr. I. ARUL, 'An analysis of opportunities and batteries of integrating renewable energy with smart grid technologies in India', First International Conference on Large Scale Grid Integration of Renewable Energy in India.

[50] A. Ritcher, Chr. Clabunde, M. Volter, Jenny Gronau, 'renewable energy forecasting optimization for system operator and trader', IEEE 2017, doi: 978-1-5386-2212-4/17/

[51] Rashmi Ranjan Behera, A N Thakur, 'an overview of various grid synchronization techniques for single-phase grid integration of renewable distributed power generation systems', International Conference on Electrical, Electronics, and Optimization Techniques (ICEEOT) - 2016, IEEE, 978-1-4673-9939-5

[52] F. Blaabjerg, R. Teodorescu, M. Liserre, A. Timbus, 'Overview of control and grid synchronization for distributed power generation systems', IEEE Transactions on Industrial Electronics, vol. 53, Issue. 5, pp. 1398-1409, Oct. 2006.

[53] S. Silva, B. Lopes, B. Cardoso Filho, R. Campana and W. Boaventura, 'Performance evaluation of PLL algorithms for single-phase grid connected systems', Conference Record of the 2004 IEEE Industry Applications Conference, 2004; 39th IAS Annual Meeting, 2004. 
[54] M. Karimi-Ghartemani, M. R. Iravani, 'A new phase-locked loop (PLL) system', in Proceedings of the 44th IEEE 2001 Midwest Symposium on Circuits and Systems, vol. 1, pp. 421-424, 2001.

[55] R. Teodorescu, M. Liserre, and P. Rodriguez, 'Grid Converters for Photovoltaic and Wind Power Systems', John Wiley \& Sons, 2011.

[56] G. C. Hsieh, J. C. Hung, 'Phase-locked loop techniques - A survey’, IEEE Trans. On Ind. Electronics, vol.43, pp.609-615, Dec.1996.

[57] M. Ashabani, F. Freijedo, S. Golestan and J. Guerrero, 'Inducverters: PLL-Less converters with auto-synchronization and emulated inertia capability,” IEEE Trans. Smart Grid, pp. 1-1, 2015.

[58] David B. Richardson, 'Electric vehicles and the electric grid: A review of modelling approaches, Impacts, and renewable energy integration', Renewable and Sustainable Energy Reviews, Vol. 19, pp. 247-254, 2013, http://dx.doi.org/10.1016/j.rser.2012.11.042

[59] Mohamed Ahmed Hassan El-Sayed, 'Smart Grid Operation with Hybrid Renewable Resources and Electric Vehicle', International Conference on Renewable Energies and Power Quality (ICREPQ'18) Salamanca (Spain), Renewable Energy and Power Quality Journal (RE\&PQJ), , No.16 April 2018, https://doi.org/10.24084/repqj16.222

[60] https://www.popsci.com/tesla-building-worlds-biggest-battery-how-it-will-work.

\section{AUTHOR PROFILE}

Jigar Sarda: He is working as an Assistant Professor in Electrical Engineering Department at CHARUSAT University, INDIA since January, 2012. He has completed his B.E. Electrical from Charotar Institute of Technology in 2009 and M.Tech. in Automation \& Control Power System from L.D.College of Engineering in 2012. Currently, he is a doctoral candidate in the Department of Electrical Engineering, CHARUSAT University, Anand, Gujarat. His research area includes Computational Intelligence methods, Smart Grid and Power System Optimization. His Proposed optimization algorithms entitled "Entropy Enhanced Covariance Matrix Adaptation Evolution Strategy (EECMAES)" had secured $2^{\text {nd }}$ ranks in IEEE PES worldwide competitions on Operational planning of sustainable power systems at Portland (USA)-IEEE PES General Meeting in 2018. His proposed algorithms entitled "GM_VNPSO" secured 3rd ranks in international competitions at GECCO 2019 and 2019 IEEE CEC at Czech Republic and New-Zealand respectively in 2019.

Dr. Kartik S. Pandya: He is working as a Professor in Electrical Engineering Department at CHARUSAT University, INDIA. His research area includes Computational Intelligence methods, Power System Optimization, Smart Grid, Renewable integrations and Power System Protection Optimization. His team had successfully executed a consultancy project of ABB entitled "Prototype Development of Switch-sync Simulator Demo Kit". His Proposed optimization algorithms entitled "Levy Differential Evolutionary Particle Swarm Optimization (Levy DEEPSO)" and "Entropy Enhanced Covariance Matrix Adaptation Evolution Strategy (EECMAES)" had secured 3rd and 2nd ranks respectively in IEEE PES worldwide competitions on Operational planning of sustainable power systems at Chicago and Portland (USA)-IEEE PES General Meeting in 2017 and 2018, respectively. His proposed algorithms entitled "EVDEPSO" and "IC_DEEPSO" had secured 2nd and 4th ranks respectively in IEEE competition at World Congress on Computational Intelligence (WCCI) 2018 conference at Brazil. His proposed algorithms entitled "HL_PS_VNSO" and "GM_VNPSO" secured 2nd and 3rd ranks in international competitions at GECCO 2019 and 2019 IEEE CEC at Czech Republic and NewZealand respectively in 2019. He has published 30 research papers in international journals and conferences. He has been awarded with "Outstanding Contribution in Reviewing" by International Journal of Electrical Power and Energy Systems published by Elsevier. 